\section{Sequenzielles Regime beim fortgeschrittenen Urothelkarzinom}

Welche Vorteile bietet eine sequenzielle Chemotherapie bei metastasiertem oder lokal fortgeschrittenem Urothelkarzinom? In einer aktuellen Studie wurden Effektivität und Toxizitätsprofil ausgewertet.

A $n$ einer Studie zur sequenziellen Chemotherapie bei metastasiertem oder lokal fortgeschrittenem Urothelkarzinom nahmen 60 Patienten teil. Bei 33\% waren viszerale Metastasen oder Knochenfiliae nachweisbar, in $25 \%$ der Fälle lagen nur Lymphknotenmetastasen vor. $37 \%$ wiesen einen unresektablen Primärtumor auf. Bei keinem war innerhalb der letzten drei Wochen eine Chemo- oder Radiotherapie durchgeführt worden. Die Patienten erhielten Doxorubicin $\left(50 \mathrm{mg} / \mathrm{m}^{2}\right)$ und Gemcitabin $\left(2.000 \mathrm{mg} / \mathrm{m}^{2}\right)$ alle zwei Wochen für zehn bis zwölf Wochen, dann Paclitaxel $\left(200 \mathrm{mg} / \mathrm{m}^{2}\right)$, Cisplatin $(70$ $\left.\mathrm{mg} / \mathrm{m}^{2}\right)$ und Ifosfamid $\left(1.500 \mathrm{mg} / \mathrm{m}^{2}\right)$ alle drei Wochen für vier Zyklen.

$73 \%$ der evaluierbaren Teilnehmer zeigten ein komplettes (19 Patienten) oder partielles Ansprechen (21 Patienten), das im Mittel 11,3 Monate dauerte. Die mediane progressionsfreie Überlebenszeit lag bei 12,1, die Gesamtüberlebenszeit bei 16,4 Monaten. Nach einer Beobachtungszeit von 76,4 Monaten waren sieben Patienten $(11,7 \%)$ am Leben, alle ohne nachweisbaren Tumor.

Die mit Abstand häufigste schwere $\mathrm{Ne}$ benwirkung war Neutropenie: $68 \%$ der Patienten zeigten hier eine Grad-3- oder
Grad-4-Reaktion. Febrile Neutropenien traten in $22 \%$ der Fälle (Grad 3) und 3\% (Grad 4) auf. Schwere Anämie oder Thrombozytopenie (Grad 3/4) wurden zu jeweils $32 \%$ beobachtet.

Fazit: Die Behandlung fortgeschrittener Urothelkarzinome mit dem sequenziellen Chemotherapie-Regime zeigte eine Ansprechrate von $73 \%$. Progressionsfreies und Gesamtüberleben lagen bei 12,1 bzw. 16,4 Monaten. Aufgrund der hohen hämatologischen Toxizität sehen die Autoren keinen klaren Vorteil dieser Therapie gegenüber anderen nicht sequenziellen Regimes auf Cisplatin-Basis. af

Milowsky Ml et al. Final results of sequential doxorubicin plus gemcitabine and ifosfamide, paclitaxel, and cisplatin chemotherapy in patients with metastatic or locally advanced transitional cell carcinoma of the urothelium. J Clin Oncol 2009; 27: 4062-7.

\title{
PCA: neuer Assay zur Früherkennung
}

\section{Das Prostata-spezifische Antigen ist seit Jahren Gegenstand kontroverser Diskussionen. Ein neuer Assay namens ProCaM stützt sich nun auf drei Methylierungsmarker im Urin.}

T ests auf Basis einer methylierungsspezifischen PCR scheinen besser mit einer Krebserkrankung zu korrelieren als das PSA. US-Forscher haben einen Assay namens ProCaM untersucht, der die Methylierung dreier Marker (GSTP1, RARb2 sowie APC) mittels PCR in Zellen aus dem Urin bestimmt. Der Urin wurde nach digital-rektaler Untersuchung von
337 Männern gesammelt, deren PSASpiegel zwischen $2 \mathrm{ng} / \mathrm{m}$ und $10 \mathrm{ng} / \mathrm{ml}$ lagen. Die Forscher testeten Sensitivität und Spezifität des ProCaM-Tests anhand histologischer Resultate nach Biopsie.

Von den 337 Probanden waren 178 an Krebs erkrankt. Die Proben wurden entweder als Ganzes oder in Teilen untersucht. Wurden ein oder mehrere Mar-

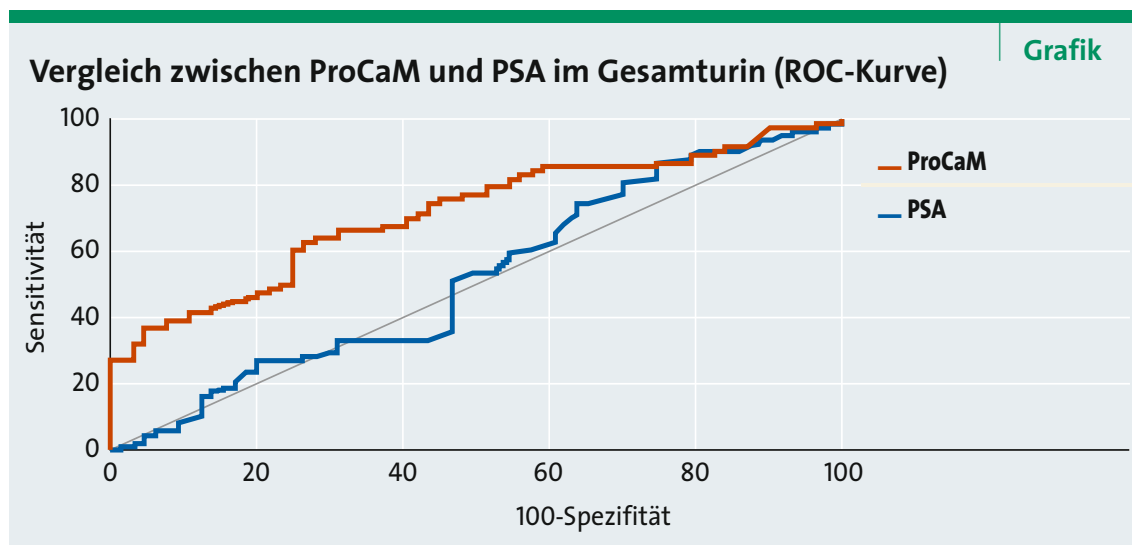

ker entdeckt, galt der Test als positiv. Alle Probanden unterzogen sich zudem einer ultraschallgestützten Nadelbiopsie.

Der Test funktionierte mit den ganzen Urin-Proben deutlich besser als mit den geteilten $(p=0,035)$. So betrug die AUC (Area under the Curve) in der Kohorte mit ganzen Urinproben 0,72 , in der kombinierten Population 0,67. Beide Werte waren höher als die des PSA-Tests, sofern ein PSA-Spiegel von 4,0 ng/ml als Grenze gesetzt wurde. Der negative prädiktive Wert des Assays in der Gesamturin-Kohorte mit PSA-Werten höher als 4,1 ng/ml betrug $87 \%$, der positive prädiktive Wert in der Kohorte mit PSA-Werten bis 4,0

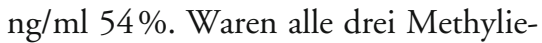
rungsmarker positiv, so war der positive prädiktive Wert höher.

Fazit: Dieser in Entwicklung befindliche Test könnte zusammen mit gängigen Screening-Algorithmen die Entscheidung für oder gegen eine Biopsie verbessern. Das Prostatakarzinom lässt sich damit offenbar im Vergleich zu existierenden Modellen besser erkennen. be

Baden J et al. Multicenter evaluation of an investigational prostate cancer methylation assay. J Urol 2009; 182: 1186-93 